$1988, \quad 37, \quad 2$

\title{
KINETICS OF PHOTOPHYSICAL HOLE-BURNING IN TETRACENE-DOPED MTHF GLASSES
}

\author{
(Presented by K. K. Rebane)
}

\begin{abstract}
Experimental data for growth and spontaneous recovery of photophysical holes burnt into the $S_{1} \leftarrow S_{0} \quad 0$-0-band of tetracene doped into a methyltetrahydrofurane (MTHF) glass are analysed in terms of the concept of a dispersive reaction, whose rate parameter is subject to a Gaussian distribution. The inherent dispersion resulting from the finite homogeneous spectral width of the absorbers as well as the random orientation of their transition moments has been evaluated explicitly. It turns out that hole-burning and recovery are kinetically correlated processes indicating that the photoactive guest-host configurations are well represented by bistable systems.
\end{abstract}

\section{Introduction}

A unimolecular reaction converting an educt $E$ to a product $P$ leads to an exponential decay of the educt concentration [E] as a function of time, provided that the rate constant is the same for all reactants. This applies to photophysical or photochemical transformation in crystalline or fluid matrices. While in the former the reaction sites are identical by virtue of the lattice symmetry, they are so in the latter case also because the memory time for a specific local configuration is usually short compared to the time scale of the reaction ensuring that momentary local fluctuations of the reaction parameters are smeared out. This is no longer true for reactions in glasses well below the glass transition temperature where the frozen-in structural disorder can be considered static on the time scale of a reaction event $\left[{ }^{1}\right]$.

The potential energy profile of a glass is a multi-dimensional surface with local maxima and minima randomly occupied by the glassconstituting elements $\left[{ }^{2}\right]$. Its basic unit can be considered as a twolevel system (TLS) $[3,4]$. Both the static and dynamic properties of the glass are determined by the TLS parameters, notably their distribution, although different properties are governed by different. TLSs. Stimulated by the temperature-dependence of the specific heat at low $T\left[{ }^{5}\right]$, it has become common practice (i) to consider tunneling transition among TLS to be the elementary excitations at low $T\left[{ }^{6,7}\right]$ and (ii) to assume a flat distribution function for both the energy separation $\Delta$ of the double well minima and the tunneling parameter $\lambda\left[{ }^{3,4}\right]$,

$$
P(\Delta, \lambda) d \Delta d \lambda=\bar{P} d \Delta d \lambda, \quad \Delta_{\min } \leqslant \Delta \leqslant \Delta_{\max }, \quad \lambda_{\min } \leqslant \lambda \leqslant \lambda_{\max } .
$$

On the other hand, the inhomogeneously broadened absorption profiles of guest molecules in random matrices $\left[{ }^{2,8}\right]$ as well as of amorphous organic bulk materials $\left[{ }^{9}\right]$ are well approximated by Gaussians. Since the oscillator strengths of molecular transitions are matrix-insensitve, the profiles represent the convolution of the density of states functions 
(DOS) for ground and excited states [ $\left.{ }^{10}\right]$. There is thus experimental evidence that DOSs of site energies in glasses are of Gaussian rather than of rectangular shape as equivalent to eq. (1). Not only is this in accord with the notion that the van der Waals interaction energy of a solute molecule is affected by a large number of internal variables, each varying randomly with only moderate statistical spread, but also with the principle that statistically varying quantities are usually represented by continuous DOS functions rather than by step functions. Remarkably, R. Jankowiak et al. $\left[{ }^{11,12}\right]$ were able to demonstrate that the assumption of Gaussian distribution functions for both $\lambda$ and $\Delta$ leads to a DOS for TLSs that is in accord with a variety of observables.

It is straightforward to conjecture that photo-induced site relaxation of guest molecule in a random matrix be governed by a distribution
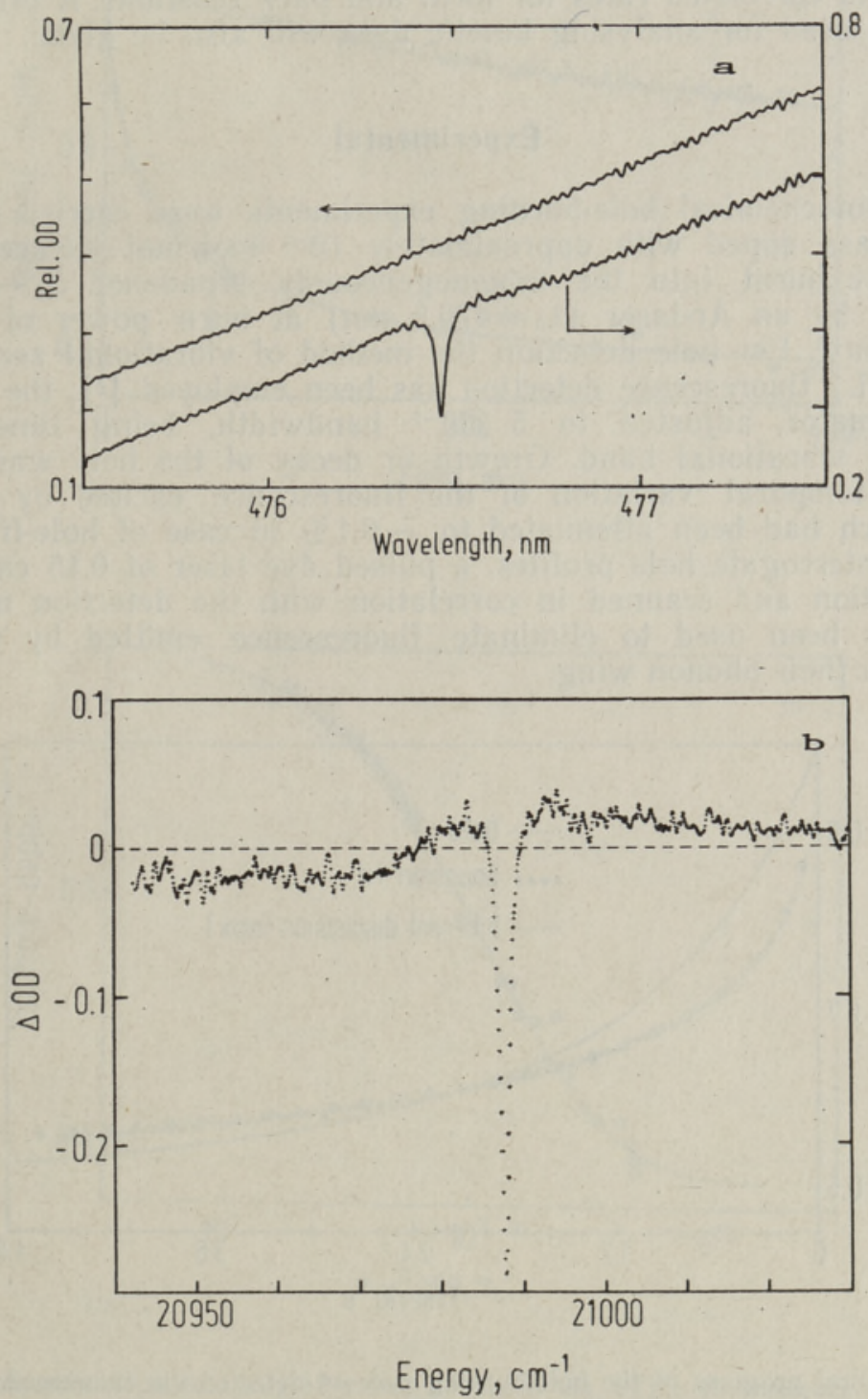

Fig. 1. $a-$ Profile of the inhomogeneously broadened TC absorption before (upper) and after (lower, offset) hole-burning. Part $b$ illustrates the relative change in optical density, exhibiting the appearence of anti-hole states at energies above the zero phonon hole and the rise of $O D$ by antiholes compensating the decrease of $O D$ by hole-burning via the phonon wing of low energy sites. 
of rate parameters giving rise to non-exponential growth of a spectral hole. Previous work $\left[{ }^{13,14}\right]$ has confirmed this notion, although the effect of intrinsic kinetic dispersion of hole-burning rates, caused by the homogeneous distribution of absorption cross sections of those chromophores that are isochromatic with the burn-laser, has been ignored $\left[{ }^{15}\right]$. In this paper the dispersion of a temporal burn-pattern is disentangled into an inherent contribution due to both the spread the absorption cross sections and the random orientation of transition moments relative to the polarization of the laser and a kinetic contribution reflecting the spread of the rate controlling parameters. We further present data on growth and spontaneous recovery of photophysical holes in a tetracenedoped MTHF glass which indicate that the guest-host configuration undergoing NPHB can to good aproximation be regarded as a bistable system with correlated rates for forth and back reactions. A brief outline of method used for analysing kinetic data will also be given.

\section{Experimental}

Non-photochemical hole-burning experiments were carried out on a MTHF glass doped with approximately $10^{-4} \mathrm{~mol} / \mathrm{mol}$ tetracene (TC). Holes were burnt into the inhomogeneously broadened $S_{1} \leftarrow S_{0} 0-0$ transition by an $\mathrm{Ar}$-laser $\left(\lambda_{b}=476,5 \mathrm{~nm}\right)$ at burn power of typically $0.5 \mathrm{~mW} \mathrm{~cm}-2$. For hole detection the method of vibrational zero phonon line (VZPL) fluorescence detection has been employed [ $\left.{ }^{8}\right]$, the detection monochromator, adjusted to $5 \mathrm{~cm}^{-1}$ bandwidth, being tuned to the $1387 \mathrm{~cm}^{-1}$ vibrational band. Growth or decay of the hole was inferred from the temporal variation of the fluorescence excited by the burn beam which had been attenuated to $\sim 0.1 \%$ in case of hole-filling studies. To interrogate hole profiles, a pulsed dye laser of $0.15 \mathrm{~cm}^{-1}$ spectral resolution and scanned in correlation with the detection monochromator has been used to eliminate fluorescence emitted by molecules excited via their phonon wing.

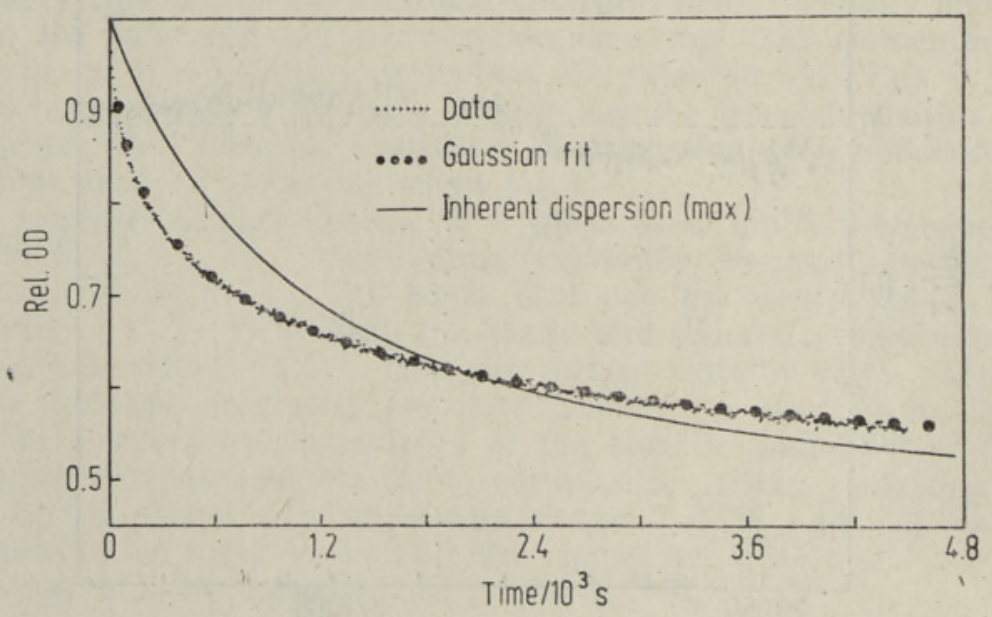

Fig. 2. Temporal progress of the hole-burning process detected via fluorescence intensity of the vibrational zero phonon line (dots). The solid line shows an upper estimate of the inherent dispersion as predicted by eq. (4) but disregarding any variations of tunneling matrix elements. A comparison with the experimental data indicates that the statistics of TLSs are essential for understanding the burn kinetics. Full circles denote the fit on the basis of eq. (4) which includes the Gaussian density of $\lambda$ and the inherent contribution to the dispersion. The fit parameters are $\sigma=2.0, v_{0}=4.2 \times 10^{-3} \mathrm{~s}^{-1}$. 


\section{Experimental results}

Fig. $1 a$ shows a section of the $S_{1} \leftarrow S_{0} 0-0$ absorption profile recorded in the VZPL fluorescence detection mode before and after burning. Note that spectra are off-set for clarity. The hole, $29 \%$. deep, is accompanied by antiholes indicating that the oscillator strength of hole-forming sites is at least partially recovered. The broad depletion feature on the low energy side is due to the sites burnt via phonon wing excita-
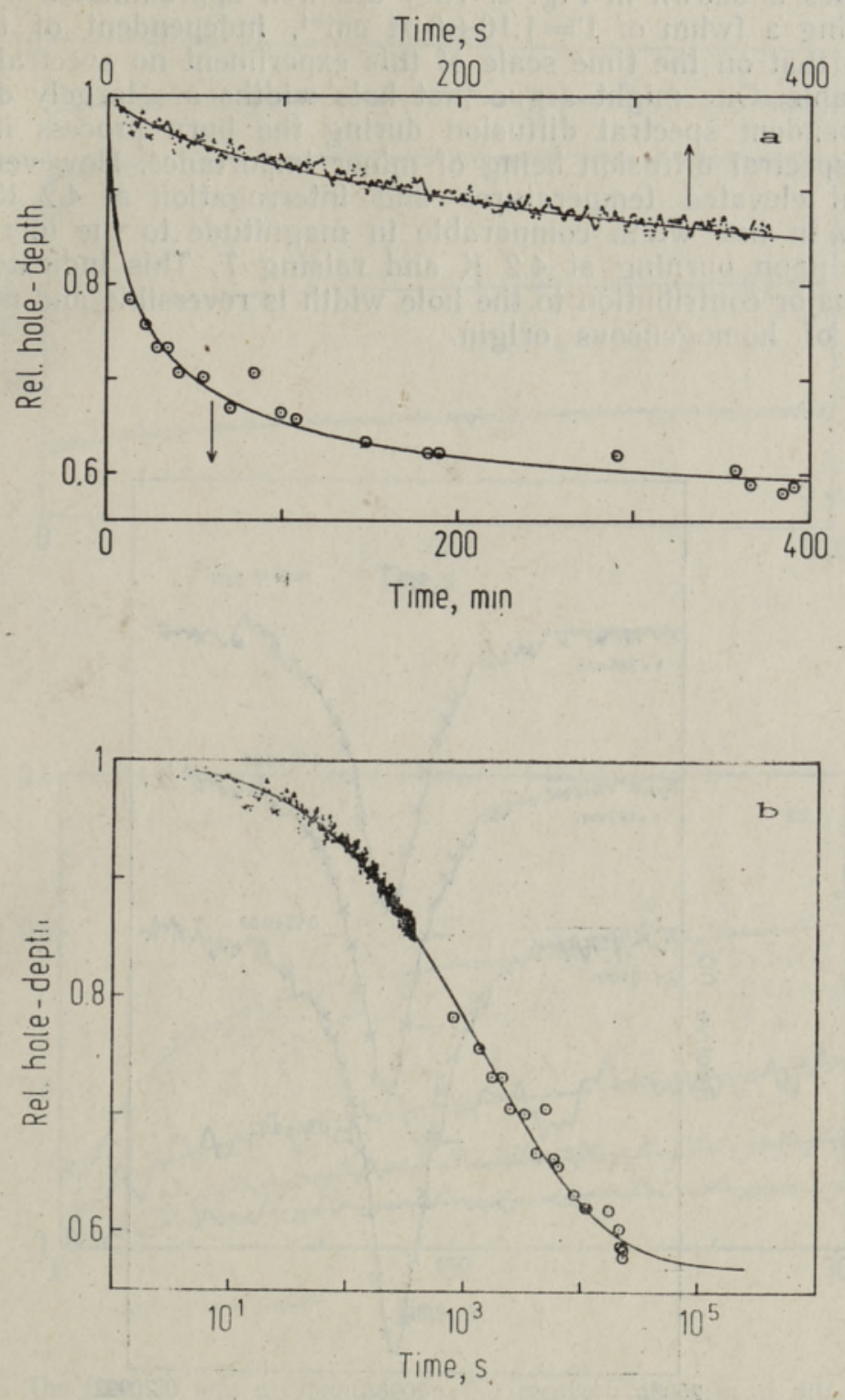

Fig. 3. $a-$ Spontaneous recovery of a hole recorded via VZPL fluorescence (dots) and scanning the hole profile (circles) in the long time regime. The solid line represents the calculated kinetics assuming a Gaussian density of turineling parameters and hole saturation at $-(\triangle O D / O D)_{\max }=0.55$, using the parameter set $\sigma=2.5, \quad k_{m}=k_{s}=$ $=1.8 \times 10^{-3} \mathrm{~s}^{-1}, k_{S P}=0.3 \times 10^{-3} \mathrm{~s}^{-1}$. Section $b$ shows data and fit curve on a logarithmic time scale. Deviations from a logarithmic decay law arè obvious in the short time limit of the experimental findings. 
tion. Hole profiles are Lorentzian if changes in the base line due to anti-hole formation is taken into account.

The depletion of chromophores in resonance with the laser as a function of burn time, presented in Fig. 2, is non-exponential in time and tends to saturate at $-\triangle O D / O D_{0} \sim 0.5$. After terminating the burn process, spontaneous hole-filling (SHF) $\left[{ }^{16,17}\right]$ sets in. A compilation of SHF data collected by continuous fluorescence monitoring within the time interval $3 \mathrm{~s}<\mathrm{t}<400 \mathrm{~s}$ and by hole profile probing afterwards is presented in Fig. 3. A selection of hole profiles recorded at different delay times is shown in Fig. 4. They are well approximated by Lorentzians having a fwhm of $\Gamma=1.10 \pm 0.04 \mathrm{~cm}^{-1}$, independent of time. This indicates that on the time scale of this experiment no spectral diffusion is detectable. One might argue that hole widths are largely determined by $T$-dependent spectral diffusion during the burn process itself, subsequent spectral diffusion being of minor importance. However, burning a hole at elevated temperatures and interrogation at $4.2 \mathrm{~K}$ yields a reduction in line width comparable in magnitude to the increase in $\Gamma$ observed upon burning at $4.2 \mathrm{~K}$ and raising $T$. This indicates that at least a major contribution to the hole width is reversible and must therefore be of homogeneous origin.

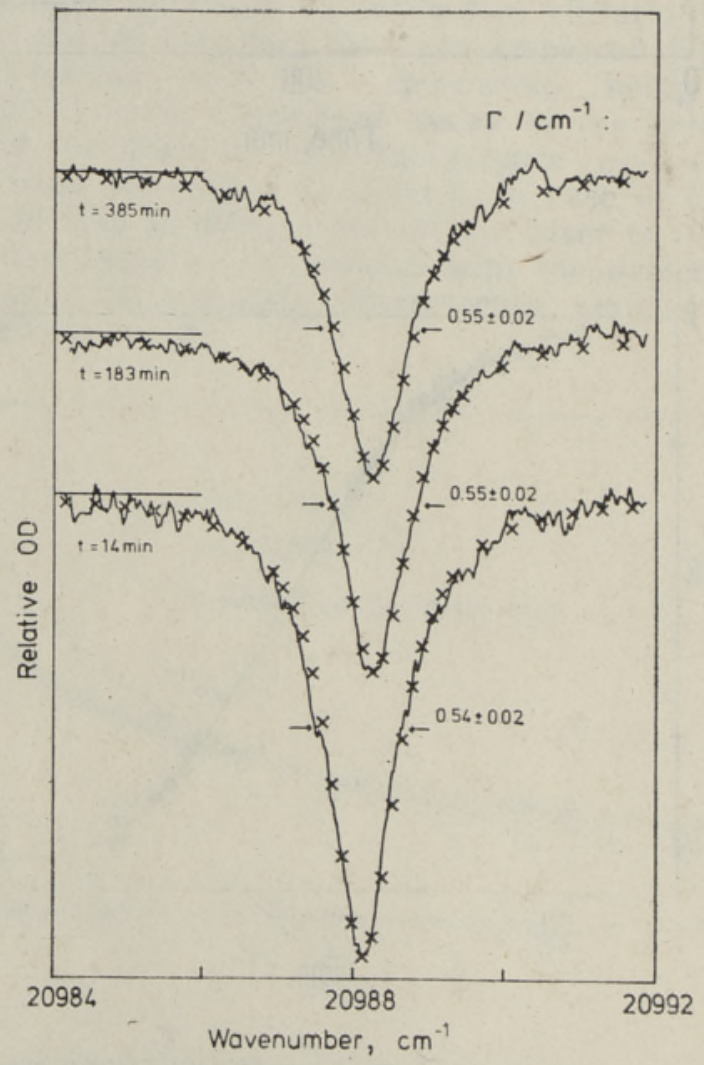

Fig. 4. Experimental hole profiles (lines) for various times after terminating the burn process as indicated, taken from the scan (circles) of Fig. 3. The holes are well approximated by Lorentzian line shapes (crosses) with constant width $\Gamma$. This demonstrates that spontaneous hole-filling is not accompanied by spectral diffusion within the time frame of Fig. 3 . 
In order to find out whether or not $\mathrm{NPHB}$ and $\mathrm{SHF}$ are correlated processes, SHF was studied as a function of the initial hole depth. The results, portrayed in Fig. $5 a$, do bear out a correlation between holeburning and refilling. The shallower the initial hole is, the larger is the rate of initial recovery and the shorter is the time for attaining saturation. This trend is more clearly seen in Fig. $5 b$ showing SHF data normalized to the initial hole depth.
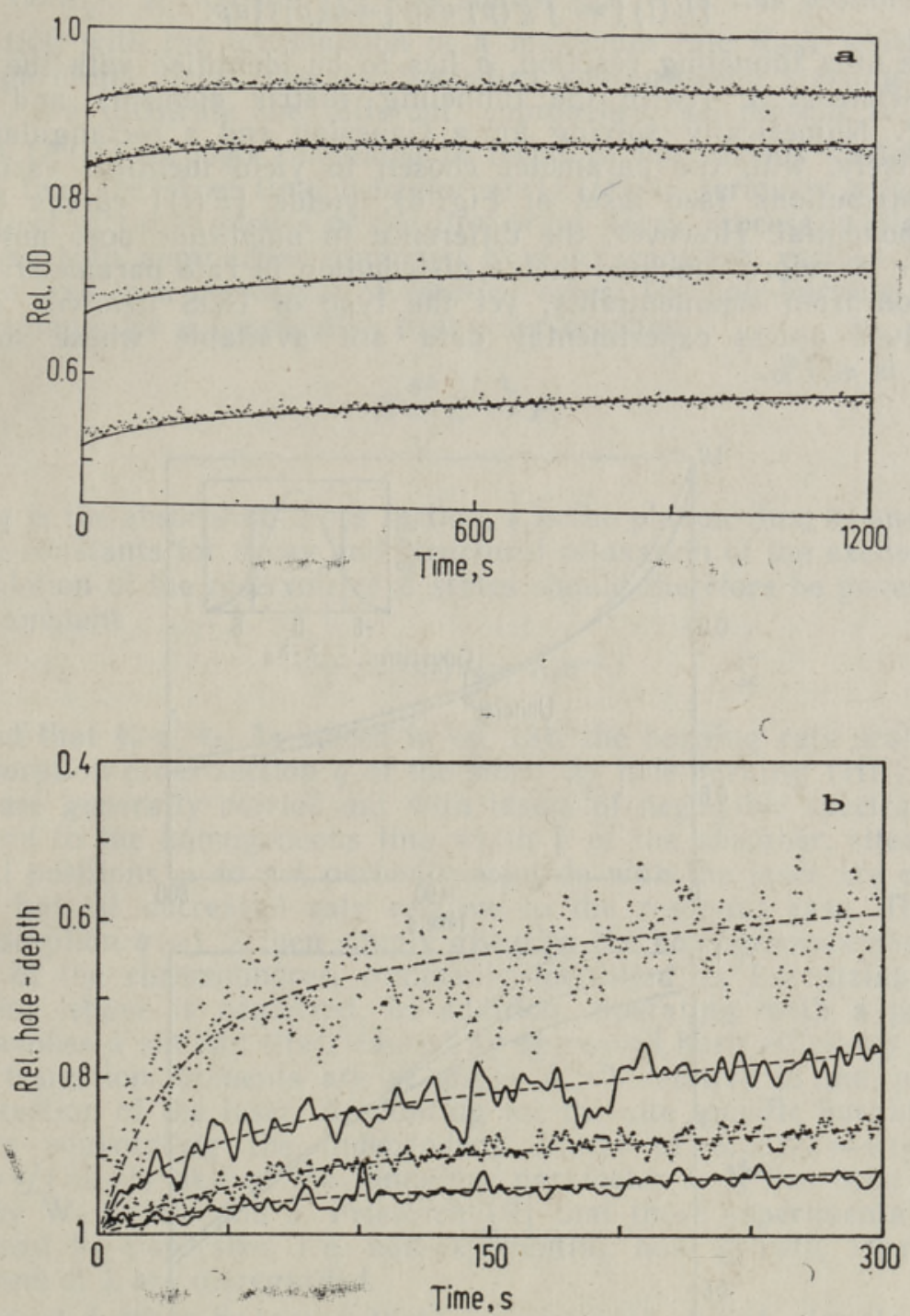

Fig. 5. $a=$ The first $20 \mathrm{~min}$ of spontaneous $O D$ recovery of holes of different depth detected via continuously recorded VZPL fluorescence (dots). Immediately after exposing the sample for burn times varying from $30 \mathrm{~s}$ to $4000 \mathrm{~s}$ and $I_{B}=0.5 \mathrm{~mW} / \mathrm{cm}^{2}$ the interrogation intensity was reduced by a factor of $10^{-3}$. Solid lines depict the fits assuming correlated burn and recovery tunneling processes choosing the parameter set (see text) $\sigma=2, k_{m}=k_{s}=0.007 \mathrm{~s}^{-1}, k_{S P}=0.001 \mathrm{~s}^{-1}$ and a maximum hole recovery of $30 \%$. $b$ - The same SHF-data yet plotted relative to the initial hole depth $(10,18,32$ and $47 \%$ from top to bottom, respectively) to illustrate that shallow holes recover faster than deep ones. Broken lines are guides to the eye not corresponding to the fits in Fig. $5 a$. 


\section{Discussion}

\section{Hole-burning kinetics}

Consider an ensemble of educt states that can be converted to a product state $P$ by a photon-induced first order transformation $P$. If the rate constant $v(p)$ of the individual reaction depends on a rate parameter $p$ that is subject to a distribution with density $g(p)$, the temporal decay of $[E(t)]$ follows

$$
[E(t)]=\int g(p) \exp [-v(p) t] d p .
$$

In case of a tunneling reaction, $p$ has to be identified with the tunneling parameter $\lambda$ (twice the tunneling matrix element) and $v(\lambda)=$ $=v_{0} e^{-\lambda}$. Numerically solving for a Gaussian and a rectangular DOS, respectively, with the parameter chosen to yield identical variance of the distributions (see inset of Fig. 6), yields $[E(t)]$ curves that are non-exponential. However, the difference in amplitude does not exceed $3 \%$. We therefore conclude that a distribution in rate parameters causes deviation from exponentiality, yet the type of DOS involved remains unresolved unless experimental data are available whose statistical scatter is $\leqslant 1 \%$.
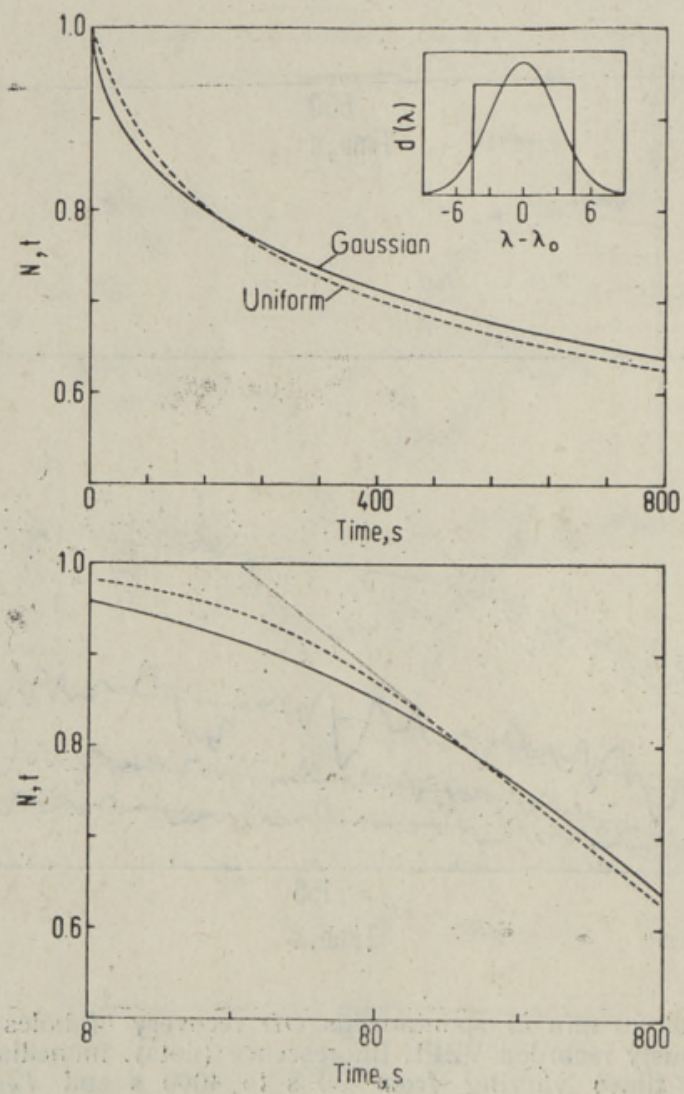

Fig. 6. Comparison of dispersive decays with Gaussian and uniform density of $\lambda$ calculated by means of eq. (2) with parameters $\lambda_{0}=10, \sigma=3$ and $v_{0}=5 \mathrm{~s}^{-1}$ (Gaussian) and $\lambda_{0}=10, \sigma=2.0$ and $v_{0}=5 \mathrm{~s}^{-1}$ (uniform), where $\sigma$ represents the square root of the dispersion in both cases. The inset illustrates both densities on a common $\lambda$-scale. A logtime representation (lower plot) compares the decay with a logarithmic law indicated by the dotted line. 
An alternative approach for analysing non-exponential relaxation patterns of first-order reactions has been developed by the Bayreuth group $\left[{ }^{18}\right]$. Adopting the strep-function approach often made in the treatment of TLSs (see eq. (1)), they retain the assumption of a rectangular DOS for the tunneling parameter. The more serious approximation, however, is the neglect of the statistics of individual event times a decaying ensemble of identical reactants is subject to. Instead of considering the exponential density of the decay probability, these authors assume that a reactant characterized by a rate $R_{0}$ will oxactly react at a time $t=R_{0}^{-1}$. R. Richert $\left.{ }^{19}\right]$ has shown that it is this assumption in conjunction with the introduction of a maximum rate $R_{\max }$ which leads to a logarithmic decay law for the educt concentration starting at $t=$ $=R_{\max }^{-1}$. To illustrate the different approaches, we present in Fig. 6 plots of $[E(t)]$ vs $\log t$ calculated in terms of the various models. It is obvious that the short time behavior of $[E(t)]$ is seriously affected by the neglect of the statistics of the first-order decay process, while in the long time both approaches converge. Next we consider various reasons that can lead to a dispersion of reaction rates. The hole-burning process is an example for a consecutive first-order reaction

$$
E \underset{k_{f_{f}}}{\stackrel{q I}{\rightleftharpoons}} E^{*} \stackrel{k_{r}}{\rightarrow} P
$$

where $q$ is the absorption cross section, $I$ is the photon flux, $k_{f}$ and $k_{r}$ are the rate constants for decay and structural relaxation of the excited educt $E^{*}$. Depletion of the reservoir of $E$ states should therefore be governed by a rate constant

$$
v=\left(k_{r} / k_{f}\right) q I=K_{0} e^{-\lambda, i}
$$

provided that $k_{r} \ll k_{f}$. As stated in eq. (3), the burning rate scales with the absorption cross section $q$ of the sites. As hole-burning (HB) experiments are generally carried out with lasers of negligible spectral width compared to the homogeneous line width $\Gamma$ of the absorber, sites whose spectral positions $\omega$ do not perfectly coincide with the laser are engaged in $\mathrm{HB}$ but, at decreased rate relative to the resonant case. The relative absorption $q(\omega)$ is then simply given by the homogeneous absorption profile of the chromophores, commonly identified as Lorentzian, if the laser line shape is neglected. In addition, operating with a polarized laser invokes a similar effect caused by decreased burn efficiency of sites whose transition moments are at angle $\delta>0$ relative to the polarization direction of the laser. Accounting for the site specific burning rates involves convoluting the independent effects of $\delta, v(\delta)=v \cos ^{2} \delta, \omega$, $v(\omega)=v /\left(1+\omega^{2}\right)$ and of the tunneling parameter $\lambda$. It has been emphasized by W. Köhler and J. Friedrich [5] that these experimental conditions lead to dispersive, i. è. non-exponential, hole growth, even if the variations of $\lambda$ are disregarded.

It must further be noted that experimental decay signals do not directly resemble the hole growth. In the case of fluorescence detection technique, commonly using the burning laser beam as excitation light, the acquired intensity arises from all sites whose homogeneous absorption profiles overlap with the laser. Consider a site at spectral position $\omega_{L} \pm \Gamma$, where $\omega_{L}$ is the laser frequency and $\Gamma$ the homogeneous linewidth of the absorber. Its effective burn intensity is one half with respect to a site at $\omega_{L}$, which gives rise to a dispersion in burning rates. On the other hand, this site will contribute to a lower extent to the fluorescence intensity, thereby concurring with the former increase in 
dispersion. These contributions to the decay pattern including the applied detection are accounted for by the decay function

$$
\begin{gathered}
{[E(t)]=q \int_{-\infty}^{\infty} \int_{-\infty}^{\infty} d \Omega d \lambda z\left(\omega_{L}-\Omega\right) \int_{0}^{2 \pi} d \varphi \int_{0}^{\pi} p_{0}(\Omega) \exp (-k t) \cos ^{2} \gamma \sin \gamma d \gamma,} \\
k=\frac{q \Phi(\lambda) I}{h \omega_{L}} z\left(\omega_{L}-\Omega\right) \cos ^{2} \gamma, \\
z\left(\omega_{L}-\Omega\right)=\frac{1}{\left(\omega_{L}-\Omega\right)^{2}+1},
\end{gathered}
$$

$p_{0}(\Omega)$ - site distribution function, $\Phi$ - photophysical yield, $q-$ effective absorption cross section.

In this case, two simplifying assumptions are made which should hold for the usual experimental conditions: the spectral width of the laser is negligible compared to the absorber's homogeneous line width and the spectral window of the fluorescence detector exceeds the homogeneous line width. This reveals eq. (4) to yield and upper estimate for the degree of inherent dispersion.

Fig. 2 shows the observed hole growth, exhibiting saturation behavior well above zero optical density. This indicates that besides background fluorescence not all tunneling transitions in the excited state lead to a stabilized TLS configuration in the ground state. Assuming uncorrelated TLSs for the ground and excited states of the absorber would result in a maximum relative hole depth of $50 \%$ since a site has equal probability to be stabilized by a tunneling transition or to relax spontaneously into its original educt state after excitation. These different reaction destinies for various TLS configurations are depicted schematically in Fig. 7. Thus accounting for a fraction of unburnable sites is done by introducing an offset to eq. (4). The result of fitting the experimental data via eq. (4) together with an offset of 0.45 is included in Fig. 2 indicating good agreement between fit and experi-

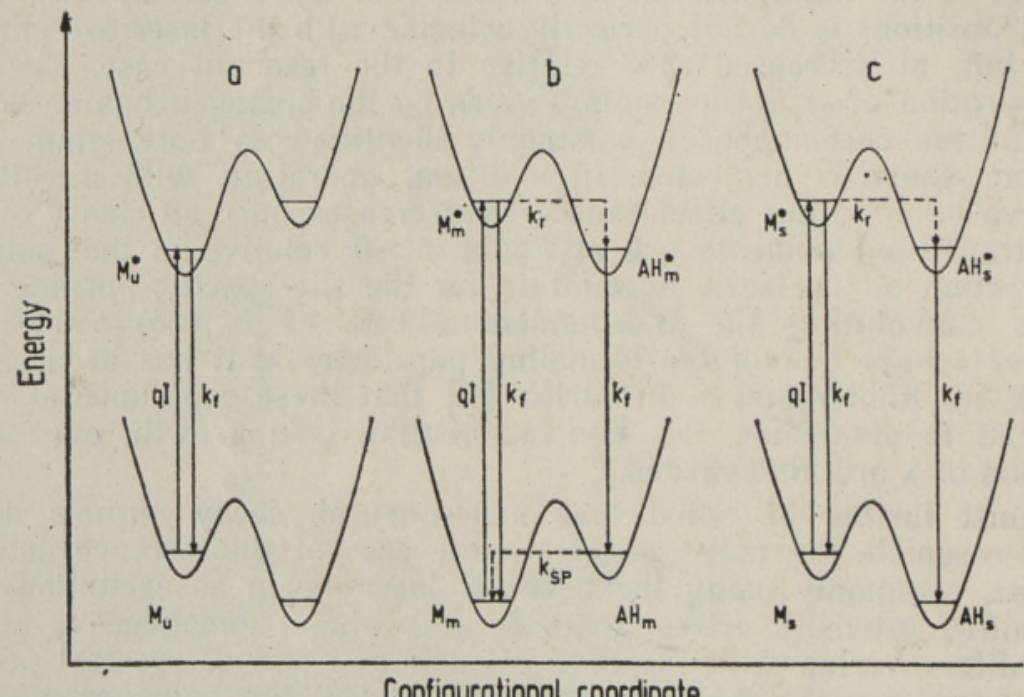

Configurational coordinate

Fig. 7. Schematic diagram of three possible TLS configurations accounting for unburnable sites $(a)$, metastable holes $(b)$ and stable holes $(c)$. The notation of states and rates agree with the kinetic scheme in the text (eq. (5)). 
mental findings after an appropriate choice of the dispersion of the tunneling parameter $\lambda$. It should be noted that experimental findings rule out that the observed dispersion can solely be attributed to the inherent effects described above (see Fig. 2).

\section{Spontaneous hole-filling}

A model developed for burning and recovery of spectral hole must be in accord with the following features: (i) only a fraction of sites isochromatic with the laser are subject to burning, (ii) only a fraction of hole are subject to SHF, (iii) there is little or no spectral diffusion involved in SHF and (iv) hole-burning and recovery must be kinetically correlated because of shallow holes, i. e. holes characterized by a large formation rate, recover on a faster time scale as compared to deeper holes. The simplest kinetic that is able to explain the above experimental facts is

$$
\begin{aligned}
& M_{m} \underset{k_{f}}{\stackrel{q I}{\rightleftharpoons}} M_{m}^{*} \stackrel{k_{r}}{\rightarrow} A H_{m}^{*} \stackrel{k_{f}}{\rightarrow} A H_{m} \stackrel{k_{s p}}{\longrightarrow} M_{m}, \\
& M_{s} \stackrel{q I}{\rightleftharpoons} M_{s}^{*} \stackrel{k_{r}}{\rightarrow} A H_{s}^{*} \stackrel{k_{f}}{\rightarrow} A H_{s}, \\
& M_{u} \underset{k_{f}}{\stackrel{q I}{\rightleftharpoons}} M_{u}^{*},
\end{aligned}
$$

with $k_{r} / k_{\mathrm{SP}}=\mathrm{const}$ and $k_{r}$ and $k_{\mathrm{SP}}$ being subject to distribution. $M_{m}, M_{s}$ and $M_{u}$ denote guest molecules that form metastable, stable and no holes, respectively, and $\mathrm{AH}$ is the antihole site correlated with $M$. Discriminating between ground state sites that form either a stable or an unstable hole/antihole pair is a logical consequence of the distribution of ground state energy levels. Consider an ensemble of sites that is accidentally degenerate with the laser tuned to approximately the average energy difference between ground and excited state. Molecules located near the high energy wing of ground state DOS will have a higher chance of relaxing into an energetically stabilized new ground state configuration than have bottom states of the DOS (see Fig. 7). An analogous argument can be used to explain existence of guest sites resistant against burning. Site relaxation, while the molecule is still in its excited state, requires that there be a state of lower energy. Since the configurations of minimum energy differ for ground and excited states, there will be little correlation and a relaxed excited site will, on the average, have an equal chance for being in a metastable or stable antihole site after electronic deactivation. If, on the other hand, site relaxation leading to $\mathrm{HB}$ would proceed in the electronic ground state, triggered, for instance, by the vibrational energy generated in the course of a radiationless $S_{1} \rightsquigarrow \rightarrow S_{0}$ transition or by a radiative FranckCondon transition to a $S_{0}^{v}$ state. followed by phonon creation, existence of unburnable sites would be difficult to explain. Moreover, one had to assume that local heating catalyzes reorientation of the guest molecule within an environment that remains unaltered. Otherwise the burn process should extinguish the site memory required for rationalizing the fact that SHF, if occurring, restores the original configuration.

The differential equations following from the above kinetic scheme had to be solved numerically in order to allow for a distribution of rate constants. To account for the observation that relative hole depths saturate at $\approx 0.55$ we assume that the fraction of burn-resistant sites 
$\left[M_{u}\right] /\left[M_{0}\right]$, is 0.45 , bearing in mind, however, that there may be other contributions to hole saturation such as a non-resonant fluorescence background of order $10 \%$. The fraction of stable holes is taken to be 0.7 and the rate parameters controlling burn and recovery process are subject to a Gaussian distribution of equal width $\sigma=2$. Optimum fit of the experimental SHF data was obtained for $k_{r}=5.3 \times 10^{-4} \mathrm{~s}^{-1}$ and $k_{r} / k_{S P}=6$ for the present choice of the burn intensity. Although the fit reveals some systematic deviations, notably in the early time require of the shallow hole data, it is remarkable that a single parameter set provides a consistent interpretation of the entire set of experimental data. An attempt to fit the data by a kinetic scheme based on the hypothesis that each $M$ site can either relax reversibly to a metastable $A H_{m}$ site or to a stable $A H_{s}$ site was unsuccessful. This supports the notion that a specific guest/host configuration can, to good approximation, be modelled by a bistable system with correlated energy barriers for burn and recovery.

We wish to point out that the fraction of stable hole/antihole sites seems to depend on the thermal history of the sample. While freshly prepared glasses gave $\left[A H_{m}\right] /\left[A H_{s}\right] \approx 1$, this ratio dropped to $\simeq 0.5$ after warming the glass to a temperature about $20 \mathrm{~K}$ below the melting point and recooling, delineating the existence of a configuration memory.

In summary we note that the concept of dispersive reactions offers a framework for rationalizing burning and recovery of photophysical holes in the MTHF(TC) system. Alleviating the problem of introducing sharp cut-off conditions in the DOS and the reaction statistics not met in real world systems, it is superior to the treatment advanced in [18].

\section{Acknowledgement}

This work was supported by the Stiftung Volkswagenwerk,

\section{REFERENCES}

1. Richert, R: Macromolecules, submitted

2. Friedrich, J., Haarer, D. Angew. Chem. Int. Ed. Engl., 23, 113 (1984).

3. Anderson, P. W., Halperin, B. I., Varma, C. Phil. Mag. B, 25, 1 (1972)

4. Phillips, W. A. J. Low Phys., 7, 351 (1972).

5. Hunklinger, S., Arnold, W. In: Physical Acoustics, 12 (eds R. N. Thurston and W. P. Mason). New York, Academic Press, 1976.

6. Hayes, J. M., Stout, R. P., Small, G. J. J. Chem. Phys., 74, 4266 (1981)

7. Hayes, J. M., Jankowiak, R., Small, G. J. In: Topics in Current Physics «Persistent Spectral Hole Burning: Science and Applications» (ed. W. E. Moerner). Berlin, Springer Verlag,' 1987.

8. Elschner, A. Bässler, H. Chem. Phys., 112, 285 (1987).

9. Jankowiak, R., Rockwitz, K. D., Bässler, H. J. Phys. Chem., 87, 552 (1983)

10. Lee, H. W. H., Walsh, C. A., Fayer, M. D. J. Chem. Phys., 83, 3148 (1986)

11. Jankowiak, R., Small, G. J., Athreya, K. B. J. Phys. Chem., 90, 3896 (1986).

12. Jankowiak, R., Small, G. J., Ries, B. J. Chem. Phys. (in press).

13. Jankowiak, R., Richert, R., Bässler, H. J. Phys. Chem., 89, 4569 (1985).

14. Aubèt, C., Fünfschilling, J., Zschokke-Gränacher, I., Siebrand, W., Wildman, T. A Chem. Phys. Lett., 122, 465 (1985).

15. Köhler, W., Friedrich, J. Chem. Phys. Lett., 134, 200 (1987).

16. Fearey, B. L., Small, G. J. Chem. Phys., 101, 269 (1986).

17. Breinl, W., Friedrich, J., Haarer, D. J. Chem. Phys., 81, 3915 (1984).

18. Breinl, W., Friedrich, J., Haarer, D. Chem. Phys. Lett., 106, 487 (1984)

19. Richert, R. J. Chem. Phys., 86, 1743 (1987). 


\section{FOTOFOUSIKALISE SALKAMISE KINEETIKA TETRATSEENILISANDIGA METOOLTETRAHUDROFURAANKLAASIDES}

On analüüsitud eksperimentaalseid andmeid fotofüüsikaliste sälkude kasvu ja spontaanse taastumise kohta, kui sälk on pōletatud tetratseenilisandiga metüültetrahüdrofuraanklaasis $S_{1} \leftarrow S_{0}$ ülemineku $0-0$-ribas. On kasutatud dispersse reaktsiooni kontseptsiooni, kusjuures kiiruse parameeter allub Gaussi jaotusele. Seejuures on arvestatud lisadispersiooni, mis on tingitud niihästi neelajate lõplikust homogeensest spektraallaiusest kui ka siirdemomentide juhuslikust suunajaotusest. Ilmneb, et sälkamine ja taastumine on kineetiliselt korreleeritud protsessid. See tōendab, et fotoaktiivsed konfiguratsioonid lisand-maatriks on hästi esitatavad bistabiilsete süsteemidena.

А. ЭЛШНЕР, Р. РИХЕРТ, Г. БЯССЛЕР

\section{КИНЕТИКА ФОТОФИЗИЧЕСКОГО ВЫЖИГАНИЯ ПРОВАЛА В МЕТИЛТЕТРАГИДРОФУРАНОВЫХ (МТГФ) СТЕКЛАХ, АКТИВИРОВАННЫХ ТЕТРАЦЕНОМ}

На основе концепции о дисперсии реакций, параметры скорости которых удовлетворяют Гауссову распределению, проанализированы экспериментальные данные для образования и спонтанного заплывания провалов, выжженных в $S_{1} \leftarrow S_{0} 0-0$ полосе молекулы тетрацена, внедренной в метилтетрагидрофурановое стекло. При этом учтена дополнительная дисперсия, происходящая как вследствие конечной однородной спектральной ширины поглотителей, так и вследствие случайных ориентаций их моментов перехода. Получено, что выжигание провала и заплывание являются кинетически скоррелированными процессами. Это показывает, что фотоактивная конфигурация примесь-матрица хорошо описывается системой, имеющей два стабильных состояния, 